\title{
Wild orchids of Tyumen and challenges, related to their preservation
}

\author{
Mariya Kazantseva $^{1 *}$, and Sergei Artyomenko ${ }^{2}$ \\ ${ }^{1}$ Institute of Northern Development Problems, Tyumen Scientific Center SB RAS, 625008 Tyumen, \\ Russia \\ ${ }^{2}$ Department of Ecology and Genetics, Institute of Biology Tyumen, State University, 625000 \\ Tyumen, Russia
}

\begin{abstract}
There are 11 plant species of the Orchidaceae family in the city area of Tyumen; eight of them are protected in the Tyumen region, one species is included in the Red Book of Russia. Representatives of the family are found in the urban forest complex, roadside forest belts, on lawns and in public gardens of the central part of the city. Most species are represented locally by single specimens or small groups; three species Epipactis helleborine, Platanthera bifolia and Neottianthe cucullata can form large complete coenopopulations. The main anthropogenous factors negatively affecting the condition of orchids in the city are: reconstruction of roads and plantations, regular mowing of grass in the habitats of plants. The protection of species requires coordinated efforts of municipal services for the improvement of urban areas and environmental organizations.
\end{abstract}

\section{Introduction}

Orchidaceae are often listed in the Red Books because of their vulnerability to human impact, leading to a decline in numbers and sometimes the complete extinction of species in impacted areas. About $60 \%$ of the species of this family that inhabit the territory of Russia are included in the Red Book of the Russian Federation; in some regions of the country this figure reaches $100 \%$ [1]. Nevertheless, some orchid species are well adapted to life near humans, claiming both preserved natural biotopes and anthropogenic habitats. In literature reports on the growth of wild orchids in urban areas can be found [2-6]. Some species even inhabit the roadsides of high-traffic roads, while being quite healthy. This shows their resistance to the most obvious negative factors of the urban environment chemical pollution of air and soil, as well as the acoustic impact and vibration, generated by traffic. The presence of orchids in the vegetation communities of urban green spaces increases their biodiversity and aesthetic attractiveness and, in general, enriches the urban flora and consortive fauna. This study is aimed at researching the diversity of orchid species in the city area of Tyumen, assessing the current state of the species and analyzing the main threats to their existence.

\footnotetext{
*Corresponding author: $\underline{\text { MNKazantseva@yandex.ru }}$
} 


\section{Material and methods}

Since 2000 the Orchidaceae were accounted for by the route method as part of the assessment of the overall biodiversity of urban green areas of Tyumen. For all accounted habitats the biotope, number of species, and their life state were indicated. Age spectrum, as well as vitality status of species, represented by sufficiently large coenopopulations, was determined using the method of Y.A. Zlobin [7] with the use of the $Q$ criterion. The method is based on the assessment of the distribution of species in the population according to their degree of development (vitality): $a$ (high), $b$ (medium) and $c$ (low). The $Q$ indicator was determined by the formula:

$$
Q=1 / 2(a+b)
$$

where: $a$ and $b$ are the proportion of species of the upper and middle classes of vitality respectively. The vitality status of a coenopopulation is assessed by comparing $Q$ and $c$ values; if $Q>c$, the population is considered prosperous; if $Q=c$, it is considered balanced, and if $Q<c$, it is considered dormant. As an indicator trait we used the height of plants of the generative age group, as the most mature and stable one.

\section{Results and discussion}

During our research within the city borders of Tyumen we observed 29 habitats (locales) of eight species of the family Orchidaceae: Epipactis helleborine (L.) Crantz. (12 locales), Platanthera bifolia (L.) Rich. (7), Malaxis monophyllos (L.) Sw. (5), Corallorhiza trifida Chatel. (1), Epipactis atrorubens (Hoffm.) Besser (1), Goodyera repens (L.) R. Br. (1), Listera ovata (L.) R. Br. (1), Neottianthe cucullata (L.) Schlechter (1). In the Tyumen area other authors also mention: Cypripedium guttatum Sw., Epipactis palustris (L.) Crantz, and Neottia nidus-avis (L.) Rich. [8]. Eight of the 11 species are included in the Red Book of the Tyumen Region [9], and Neottianthe cucullata - in the Red Book of Russia [10].

The Orchidaceae are mainly found in the urban forest complex of the city, which is based on the preserved areas of zonal forest vegetation. This is where the plants are in their natural habitat and tend to be in good living condition. Most of the orchid species found in the forest parks do not attract the attention of visitors; their injuries are rare and incidental in nature. Here the most significant impact on plants are associated with landscaping and vegetation restoration works. For example, the felling of trees and building of an asphalt road in one of the city's forest parks led to swamping of the surrounding area. As a result, a unique population of Malaxis monophyllos, which consisted of several dozens of specimens, has disappeared. It is quite rare for this species; more often it is found as individual plants.

Quite a few orchid discoveries are related to roadside forest belts confined to the outskirts of the city. Mostly it is a multi-row planting of Populus balsamifera L. with a second row of various species of shrubs. Epipactis helleborine and Platanthera bifolia (sometimes together) are most common here. They can form large coenopopulations of several hundred specimens. The only habitats of Epipactis atrorubens and Listera ovata were also observed here. There is no special care for plantations in forest belts, which contributes to the proper preservation of plants under the tree canopy. Only individual specimens of Epipactis helleborine are affected, as they move away from under the tree canopy towards the roadway, where they are often destroyed by roadside mowing. Road and public transport stops reconstruction also pose a threat to the forest belts' plants. As a result, the only habitat of Epipactis atrorubens near the bus stop was completely destroyed. Coenopopulation of Epipactis helleborine in the same area decreased its number by more 
than 7 times (from 87 specimens in 2001 to 12 specimens in 2020). Another coenopopulation of this species completely disappeared when the road was widened.

Of all the orchid species noted, only two (Epipactis helleborine and Platanthera bifolia) are found in the central part of the city, where they develop lawns and public gardens. Here Epipactis helleborine forms cenopopulations of various sizes, Platanthera bifolia is observed as isolated specimens. In these habitats, plants are the most vulnerable. A primary and most critical concern is the regular mowing of lawns, which prevents plants from finishing blooming and forming fruit. For this reason, Epipactis helleborine completely disappeared in 2 of the 4 habitats, that were located on open lawns. Plants are more successfully preserved in public gardens, protected by trees and shrubs, where grass is cut less regularly and not as thoroughly.

In the summer of 2020 we surveyed five coenopopulations (CP) of three orchid species, whose population numbers allowed for statistical analysis (Table 1). CP No.1 is found in the most difficult living conditions - in a public garden; a number of the plants here are destroyed each year by mowing. Nevertheless, the coenopopulation steadily maintains its position throughout the whole period of surveillance - for more than 10 years. In the forest belts (CP No.3 and No.4) there is no mechanical impact on plants, the negative impact is caused by the nearby road. CP No.4 and No.5 in the forest park area experience a slight recreational load.

Table 1. General characterization of the examined orchid coenopopulations

\begin{tabular}{|c|c|c|c|c|}
\hline Species & No. CP & Habitat & Numbers, sp. & $\begin{array}{c}\text { Density, } \\
\text { sp./sq.m. }\end{array}$ \\
\hline \multirow{2}{*}{ Epipactis helleborine } & No.1 & public garden & 338 & 0.10 \\
\cline { 2 - 5 } & No.2 & forest belt & 233 & 0.20 \\
\hline \multirow{2}{*}{ Platanthera bifolia } & No.3 & forest belt & 82 & 0.51 \\
\cline { 2 - 5 } & No.4 & forest park & 102 & 1.36 \\
\hline Neottianthe cucullata & No.5 & forest park & 266 & 9.50 \\
\hline
\end{tabular}

In all surveyed plots, species are represented by normal complete coenopopulations (fig.), which remain in a stable condition and are capable of self-maintenance by seed (mostly) and vegetative means. In all cases individuals in the virgil and generative ontogenetic state dominate. The absence of postgenerative specimens is typical for the orchid species in question.

An evaluation of the vitality status of the coenopopulations revealed that most of them belong to the thriving category and one of them to the balanced category (Table 2). In all cases specimens with high and medium vitality quantitatively predominate. This demonstrates that the living conditions of the species in these habitats are perfectly in line with their biological needs. 


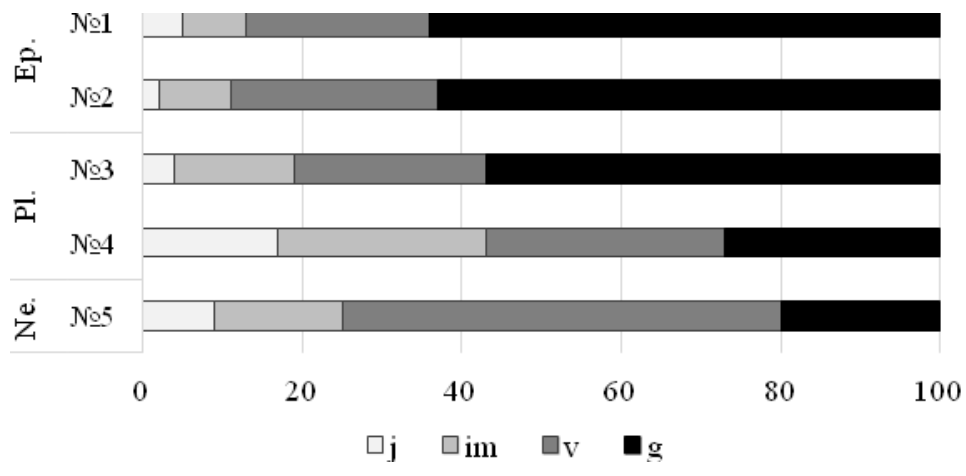

Fig. Correlation of the main age groups in orchid populations, Epipactis helleborine (Ep.),

Platanthera bifolia (Pl.) and Neottianthe cucullata (Ne.), \%. Age groups: $\mathrm{j}$-juvenile, im - immatur, $\mathrm{v}$ - virgil, g - gerative.

Table 2. The ratio of generative specimens in orchid coenopopulations by vitality classes and the $\mathrm{Q}$ index

\begin{tabular}{|c|c|c|c|c|c|c|}
\hline \multirow{2}{*}{ Species } & \multirow{2}{*}{ No.CP } & \multicolumn{3}{|c|}{$\begin{array}{l}\text { The percentage of specimens by } \\
\text { vitality classes, } \%\end{array}$} & \multirow{2}{*}{$Q$} & \multirow[t]{2}{*}{ Population type } \\
\hline & & $a$ & $b$ & $c$ & & \\
\hline \multirow{2}{*}{ Epipactis helleborine } & No.1 & 24.0 & 64.0 & 12.0 & 44.0 & thriving \\
\hline & No.2 & 70.6 & 13.7 & 15.7 & 42.2 & thriving \\
\hline \multirow{2}{*}{ Platanthera bifolia } & No.3 & 16.6 & 50.0 & 33.3 & 33.3 & balanced \\
\hline & No.4 & 17.9 & 57.1 & 25.0 & 37.5 & thriving \\
\hline Neottianthe cucullata & No.5 & 6.5 & 76.1 & 17.4 & 41.3 & thriving \\
\hline
\end{tabular}

The most important results are those related to to CP No.1-3. They demonstrate that certain representatives of the orchid family can successfully inhabit secondary biotopes of human origin located in the city. Epipactis helleborine and Platanthera bifolia, found here, are the most adapted to urban living conditions.

\section{Conclusion}

Thus, some species of the orchid family are fit for living in the landscaped areas of the city, and some of them are even able to form large viable populations under increased mancaused impact. Ironically, the main negative aspect that leads to the reduced number of orchids in Tyumen's green spaces and the extinction of some of their populations, is the activity of municipal services in urban landscaping and the maintenance of green spaces.. Obviously, the design and execution of such activities should be coordinated with environmental organizations designed to protect rare plant species and contribute to the conservation of biological diversity of ecosystems, including urban ones.

The study was carried out within the framework of the state task: project No. 121041600045 of the Tuymen Research Center of the Siberian Branch of the Russian Academy of Sciences 


\section{References}

1. P. G. Efimov, Biosphere 2 (1) (2010)

2. M. G. Vakhrameeva, T. I. Varlygina, I. V. Tatarenko, Orchids of Russia (biology, ecology and protection) (Moscow, KMK, 2014)

3. N. S. Balakhonova, E. A. Karpukhina, Russian Peoples Friendship University, 1(13) (2006)

4. E. S. Pushai, Bulletin of the Tver State University, Series Biology and Ecology, 4 (2007)

5. M. N. Kazantseva, Orchids in the man-made landscape. Specially protected natural areas of Altai Krai and neighboring regions, tactics of species diversity and gene pool conservation, October 27-29, Barnaul (1999)

6. M. N. Kazantseva, Reporter of ecology, forestry and landscape science, 3 (2002)

7. Y. A. Zlobin, Ecology, 2 (1980)

8. V. A. Glazunov, N. V. Khozyainova, E. Y. Khozyainova, Phytodiversity of Eastern Europe, 4 (2020)

9. Red Book of the Russian Federation (plants and mushrooms) (KMK Scientific Press Ltd., 2008)

10. Red Book of the Tyumen Region: animals, plants, mushrooms (Ed.-in-chief Petrova O.A. Yekaterinburg: Urals University Press, 2004) 